\title{
The use of data-driven technologies for customer-centric marketing
}

\section{Mark Anthony Camilleri}

\author{
Department of Corporate Communication, \\ Faculty of Media and Knowledge Sciences, \\ University of Malta, \\ Msida, MSD2080, Malta \\ and \\ The Business School, \\ University of Edinburgh, \\ Bucchleuch Place, Edinburgh, EH8 9JS, Scotland, UK \\ Email: mark.a.camilleri@um.edu.mt
}

\begin{abstract}
The latest technologies are shifting how businesses capture, analyse and distribute data from the individual users' online activity. Therefore, this contribution critically reviews the latest developments on big data analytics and programmatic advertising. Moreover, it sheds light on the use of blockchain; as this distributed ledger technology provides secure, verified transactions among marketplace stakeholders. The findings suggest that the service providers are increasingly utilising data-driven technologies including programmatic advertising tools to target and re-target individuals online or on their mobile. However, individuals and organisations are becoming increasingly aware on data protection issues, as they often block marketers from tracking them and serving them ads. In conclusion, this contribution puts forward a theoretical framework that explains how, why, where and when practitioners are capturing, analysing and distributing data. In sum, it implies that the data-driven technologies are facilitating the businesses' customer-centric marketing.
\end{abstract}

Keywords: big data; analytics; programmatic advertising; customer-centric marketing; blockchain; data-driven marketing; digital media.

Reference to this paper should be made as follows: Camilleri, M.A. (2020) 'The use of data-driven technologies for customer-centric marketing', Int. J. Big Data Management, Vol. 1, No. 1, pp.50-63.

Biographical notes: Mark Anthony Camilleri is a Senior Lecturer from the Department of Corporate Communication at the University of Malta. He has completed his $\mathrm{PhD}$ (Management) in three years' time at the University of Edinburgh and an MBA from the University of Leicester. He is a scientific expert in research for the Ministero dell' Istruzione, dell' Universita e della Ricerca in Italy. He is an editorial board member in a number of Springer and Inderscience journals. He has published in high-impact, peer-reviewed journals, chapters and conferences. 


\section{Introduction}

The ongoing advances in technology have brought significant improvements in the processing speed and storage of large volumes of data. Tech-savvy organisations have already started using big data with a goal to improve their decision-making, agility, and customer-centric approaches (Erevelles et al., 2016; George et al., 2014). Today, many marketers are hyper-targeting consumers through real-time mobile ad campaigns to drive conversions. They use analytics to identify how exogenous variables, including; the broader economy, competitive offerings, and even the weather can affect their organisational performance (Akter et al., 2016). Similarly, the smaller enterprises are economically gathering and storing data from each and every customer transaction. They use analytics to customise their offerings and improve their customer engagement (Ransbotham and Kiron, 2018).

Therefore, this paper builds on the previous theoretical underpinnings on smart technologies, including big data and analytics (Li et al., 2017; Baesens et al., 2016; Gretzel et al., 2015; Buhalis and Amaranggana, 2013). It clarifies how disruptive technologies have led to endless opportunities for networked businesses to gain a competitive advantage. It explains how they are leveraging themselves by utilising contemporary marketing strategies and tactics that are customer-focused. Specifically, this contribution examines the use of big data, analytics, programmatic advertising and blockchain technologies. It adds value to academic knowledge as it presents a theoretical framework that clarifies the data processing cycle. It shows how practitioners capture, analyse and distribute data. In conclusion, this paper outlines the implications for practitioners and identifies future research avenues in the realms of data-driven marketing.

\section{The uses of big data and analytics}

For decades, organisations have been gathering and analysing digital data in some way or another, to improve their performance (Ji-fan Ren et al., 2017; Akter et al., 2016; George et al., 2014). The new advantages of crunching big data analytics are based on the discovery of how to improve productivity levels and agility to enhance the businesses' financial performance (Wang et al., 2018b; Chen and Zhang, 2014). The latest technological advances have enabled many businesses, including airlines and hotels to manage their operations in a more efficient and economical way (Pan and Yang, 2017; Liu et al., 2017). For instance, several airlines and hotels are increasingly using revenue management systems that are quickly adjusting offers (Pan and Yang, 2017). The pricing of their products is usually based on a variety of situations and circumstances, as they optimise communications and transactions. By using data and analytics on the customers' behaviours, many travel businesses are taking advantage of channel-based distribution. Hence, the distribution networks have come a long way from the ticket counter. Evidently, travel and tourism businesses are leveraging themselves with data-driven marketing, as they seek new customers and prospects (Camilleri, 2018a, 2018b). They may decide to target high-yield customers through elaborated pricing and revenue management systems. Hence, the travel distribution is evolving from its current passive, rigid, and technology-centric state to a more flexible, dynamic, and passenger-centric 
environment as airlines and hotels monitor and detect any changes in their consumers' behaviours.

The terms of 'big data' and 'analytics' are increasingly being used to describe datasets and analytical techniques in applications ranging from sensors to social media that require advanced and unique storage, management, analysis, and visualisation technologies (Boyd and Crawford, 2012; Chen et al., 2012). There are a number of concepts, including; volume, variety, velocity, veracity and value that are associated with big data (Grover et al., 2018; Côrte-Real et al., 2017). Usually, big data analytics are dependent on an extensive storage capacity and processing power, requiring a flexible grid that can be reconfigured for different needs (Stergiou et al., 2018; Erevelles et al., 2016). Information technology (IT) systems may reveal valuable insights on the businesses' customers. They can indicate which products or services are sought by customers. For instance, they may reveal where and what customers eat, where and when they go on vacation, how much products they buy, etc.

Big data environments ought to make sense of the content they gather. This means that IT applications need to scrutinise and report on a wide variety of dimensions; including customer interactions, product usage, service actions and other dynamic measures. Such content may include; text messages, document images, pictures, video clips, web logs, etc.). The explosion of online and mobile activity ranging from ecommerce and social media has led to the dissemination of meaningful data that is being created online (Li et al., 2017).

\section{Capturing data}

The business environment is currently witnessing a sea of change in IT activity (Baesens et al., 2016). The expansion of big data use has been generated by the web and its online communities. Ecommerce vendors including Amazon and eBay have surely transformed the market through their innovative and highly scalable e-commerce platforms and product recommender systems. Moreover, internet giants like Google and Facebook are leading the development of web analytics, cloud computing and social media platforms. The emergence of user-generated content on fora, newsgroups, social media networks and crowd-sourcing platforms have offered endless opportunities for researchers and practitioners to 'listen' to marketplace stakeholders; including customers, employees, investors and the media (Abbasi et al., 2016). As a result, businesses are increasingly collecting and analysing data from various sources to improve their customer-centric marketing (Côrte-Real et al., 2017).

The online review sites and personal blogs provide opinion-rich information that may be explored through textual and sentiment analysis (Gao et al., 2018; Xiang et al., 2017; Cambria, 2016). Social media analytics are increasingly capturing fast-breaking trends on customer sentiments about products, brands and companies. Businesses may take advantage of these insights as it is in their interest to get to know whether there are changes in consumer behaviour and how it may correlate with changes in sales over time. In big data environments it's important to analyse, decide and act expeditiously (Baesens et al., 2016). Businesses should be quick in their decision-making and have to take remedial action, if necessary. They may have to establish specific processes which determine alternative courses of action. 
Successful businesses regularly analyse their customer service records. They gather data on the consumer sentiment toward products and brands as they continuously monitor the marketing environment (Cambria, 2016). They may collect data in real-time and use it well to personalise every aspect of their users' experience. Data-driven organisations strive to understand their customers' personas so that they target them the right content with the relevant tone, imagery and value propositions (Grover et al., 2018). Usually they take advantage of the consumers' cognitive behaviour as they try to uncover consumer frailty at their individual level (Boucher Ferguson, 2013). It may appear that many companies are increasingly gathering data on their customers as they try to understand their needs, wants and desires. They may use big data to delve into the enormous volumes of information that they collect during sales transactions in their day to day operations. The companies may use what they know about human psychology and consumer behaviour to set prices, draft contracts, minimise perceptions of danger or risk, or extract as much information as possible from their consumers (Boucher Ferguson, 2013).

In this day and age, marketing automation is helping businesses to engage with individuals whether they are customers or not. Behavioural targeting is nothing new in digital marketing. When firms hold detailed information about their consumers, they may customise every aspect of their interaction with them. Direct marketing tactics could prove as the most effective way how to reach consumers, when it is used wisely and diligently. There is scope for business to consider using data-driven marketing. Many firms have learned how to use databases as they gather valuable information in order to communicate with customers and prospects (Côrte-Real et al., 2017). Businesses could use databases to deliver promotional content to remind customers on their offerings. Eventually, the gathered data may translate to new revenue streams and can possibly build long-term loyalty. The consumer lists whether they are automated or in the cloud should always be used to deliver enhanced customer experiences. Technology is instrumental for today's businesses in their ongoing interactions with people. Nevertheless, such marketing practices could possibly lead to unnecessary nuisances to the customers. Online users are frequently bombarded with marketing endeavours including e-mail promotions that are often picked up as spam. Therefore, one-size-fits-all messages could have negative implications on prospective customers.

Large technology conglomerates are increasingly using anonymous, cookieless data capture methods to gather the consumers' data. Very often, they track the individual users' movements as they measure traffic and other real-time phenomena (Fong et al., 2015). They may be using browsing session data combined with the consumers' purchase history to deliver 'suitable' items that consumers like. As more consumers carry smartphones with them, they are increasingly receiving compelling offers that instantaneously pop up on their mobile devices. Recent advances in mobile communication and geo-positioning technologies have also presented marketers with a new way how to target prospects, based on their location. Location-targeted mobile advertising involves the provision of ad messages to cellular subscribers. This digital technology allows marketers to deliver ads and coupons that are customised to individual consumers' likings, geographic location and the time of day. Given the ubiquity of mobile devices, location-targeted mobile advertising seems to offer tremendous marketing benefits (Frizzo-Barker et al., 2016). The consumers who have social media apps on their smartphone are usually indicating their geo location as they move out and 
about. This same data can be used to identify where people gather. Such information may be valuable to brands as they seek to improve their consumer engagement and marketing efforts. Yet, to date there has been little empirical evidence about the immediate and cumulative effectiveness of such mobile advertising (Malthouse and Li, 2017).

EMarketer (2018) forecasted that mobile spending would account for about 82.5 of all US digital display ads. Notwithstanding, mobile marketers like Google or Facebook are benefiting of the smart phones and tablets' geo-location capabilities. Large technology giants use geolocation capabilities to capitalise on these mobile technologies as they leverage location and context to obtain better information on shopping habits, lifestyle preferences and the like (Aksu et al., 2018). At the same time, the consumers are becoming increasingly acquainted with these data-driven marketing technologies. Therefore, they may decide to block advertisers and publishers from serving them unwanted ads. There may be customers who may be wary of giving their personal data due to privacy concerns. Recently, The New York Times and The Observer reported that a British consulting firm, namely; Cambridge Analytica had acquired and used the personal data of thousands of Facebook users who explicitly shared their data via a third-party app. As a result, Cambridge Analytica accessed these individuals' information and obtained other data on their friends via Facebook. These Facebook users should have known very well what they were getting into. Out of their own volition, they consented a third-party app to use their personal data.

Very often, the advances in technology are faster than legislation and its deployment, as the use of digital data pushes the limits of consumer protection law. For the time being, there are different regulatory guidelines, and they are still geographically-fragmented. As a result, there are different level playing fields across various jurisdictions. For instance, the European Union (EU) Parliament has put forward its General Data Protection Regulation (GDPR) that became effective as of the 25th May 2018. In sum, the GDPR has replaced the Data Protection Directive 95/46/EC. The GDPR was designed to harmonise the data privacy laws across EU countries; to protect their citizens from privacy and data breaches, in an increasingly data-driven world (EU, 2018; Goddard, 2017). The GDPR applies to all companies processing the personal data of online users (that are referred to as the subjects, residing in the EU). It transpires that the organisations that will breach the EU's GDPR can be fined up to $4 \%$ of annual global turnover or $€ 20$ million (whichever is greater). This is the maximum fine that can be imposed for the most serious infringements, like not having the customers' consent to process their data, or for violating the core of 'privacy by design' concepts (EU, 2018). This EU regulation has strengthened the conditions for consent as companies will no longer be allowed to use long illegible terms and conditions; as the request for consent must be presented in an accessible form. Therefore, the online users' consent or withdrawal of consent, must be presented in clear and plain language.

GDPR stipulates that the subjects have a right to obtain confirmation from the data holder as to whether or not their personal data is being processed, as organisations should explain where and for what purpose they are collecting the data. The data holders are expected to provide a copy of the personal data, free of charge, in an electronic format; if this data is requested by the subjects. Notwithstanding, the subjects can ask the data holders to erase their personal data, cease further dissemination of their data, and potentially third parties should not be allowed to process this data. Therefore, the gathered data will no longer remain relevant for its original purposes without the subjects' consent. 


\subsection{Analysing data}

Organisations can always make use of the consented data that was voluntarily provided to them by the online users. However, they may avail themselves of other data sources from the macro environment, including; competitive activities, marketing actions, customer service records, etc. They may use analytics to create a good picture of their marketing performance, as it can provide them with important insights for their customer-centric strategies (Akter et al., 2016). Companies can use the gathered data for many purposes. They could quantify the contribution of each element of advertising; run scenarios for business planning; and allocate resources across marketing activities. Organisations need to adopt a more continuous approach to analysis and decision-making that are based on a series of hunches and hypotheses in real-time monitoring contexts (Davenport, 2014; Davenport et al., 2012).

The analytics software could provide detailed information on sales data and advertising metrics, by medium and location. A data analysis of one campaign may reveal that the marketing communications may work independently of one another (Camilleri, 2015; Nichols, 2013). The latest analytics packages can even reveal the impact of the companies' marketing activities in different media. This happens because the consumer behaviours might change in response to the advertising stimuli. For instance, an analysis could pick up a spike in consumers' clicking through online banner ads, after they have watched a TV ad, came across a social media placement or experienced an in-store promotion (Kumar et al., 2017). Therefore, analytics can reveal the 'assist effects' of the traditional marketing communications on digital media (Cheng and Edwards, 2015).

Once the marketers have quantified the relative contribution of each marketing communications channel, they may use predictive-analytical tools to run scenarios for business planning (Wang et al., 2016; Siegel, 2016). These analytics reveal the implications of increasing or decreasing marketing expenditures to optimise the marketing mix, and to guide the spending allocation on particular media. The statistical models could shed light on the effect of advertising on the consumers' behaviours as they may reveal the relationships (if any) with the market conditions, other marketing communications, and competitive activities. Data on the consumers' response to the marketing activities must be fed into the analytics' systems to fine-tune the corporate spending through different media. Such optimisation software can generate realistic contexts along with relevant marketing recommendations to achieve them. For example, the analytics software can test specific what-if scenarios, measure outcomes, validate models, and make corrections before making corporate decisions (Siegel, 2016). Today's marketers can readily adjust or re-allocate online advertising budgets in different markets in a fraction of a second (Camilleri, 2018c). Analytics will help them understand which marketing activities are driving leads to websites, and intermediaries.

Today's companies are in a position to quantify the precise combination of ads that will be the most effective (Kumar et al., 2017). They can identify how advertising of one product category influences the purchasing of others. Therefore, firms are already benefiting from such information, as they make fact-based decision-making when they allocate resources for their advertising and promotions (Malthouse and Li, 2017). They can also monetise data by increasing revenue whilst reducing expenses. In addition, the gathered data may be used to improve the speed to market and to enhance customer service levels (Woerner and Wixom, 2015; Kwon et al., 2014). 
Many businesses are increasingly recognising the value of building data-driven organisational cultures as they are increasingly dealing with massive volumes of data, analytics, algorithms and user interfaces (Grover et al., 2018; Hartmann et al., 2016). Some firms have experienced optimal results after they have integrated analytics within their core businesses' operational and production tasks (Abbasi et al., 2016; Loebbecke and Picot, 2015).

However, the greatest barrier to achieving this is the management and employee' attitudes toward technology and change (Russell Neuman et al., 2014; Andrejevic, 2014). Therefore, organisations should train and recruit competent individuals with new digital literacies. Recently, there has been an ongoing requirement for skilled professionals in data-driven marketing. Tomorrow's marketing employees should be knowledgeable in computer science, management information systems or network-oriented social sciences (Horlacher and Hess, 2016; Davenport et al., 2012). Highly qualified individuals are expected to support the businesses' data and information management. In some service sectors, data scientists have to become an integral part of the research and development team (Horlacher and Hess, 2016).

In the past, the marketing information systems function involved monitoring, controlling processes and notifying management about anomalies. The most vaunted business and IT capabilities used to be stability and scale (Davenport et al., 2012). Today, the analysis of data can be categorised as descriptive, predictive analytics, and prescriptive analytics (Wang et al., 2016; Deka, 2016; Halavais, 2015; Ransbotham et al., 2015; Camilleri, 2015). Descriptive analytics focus on what happened in the past. Very often, it can explain why it happened. Predictive analytics uses models to forecast the future (Fu et al., 2018), as data models could quantify the likelihood that a particular person will do something in the foreseeable future - whether it is defaulting on a loan, upgrading to a higher level of cable service or seeking another job (Camilleri, 2015; Siegel and Davenport, 2013). It may appear that predictive analytics anticipates human behaviours that have not happened as yet (Fu et al., 2018). For instance, predictive tools and smart cards have enabled Singapore Land Transit Authority to provide a more convenient transportation system to commuters and leisure passengers. Siegel and Davenport (2013) explained how quantitative techniques can be deployed to find valuable patterns in data that can enable companies to predict the likely behaviour of customers, employees and others. They distinguished between forecasting and predictive analytics. They maintained that forecasting could estimate future sales, whereas predictive data will provide additional details on customer personas, segments and prospects. Siegel and Davenport (2013) referred to the 'prediction effect' as they suggested that minor increases in the data accuracy of predictions can often lead to substantial savings in the long-term.

Prescriptive analytics anticipates what will happen, when it will happen, and explains why it will happen (Deka, 2016). Therefore, it prescribes better decision options. Although, individuals tend to regularly repeat their habitual behaviours, (for the time being) predictive analytics cannot determine when and why they may decide to change their future preferences. Yet, the possibility of 'one off' events must never be discounted (Gandomi and Haider, 2015). 


\subsection{Distributing data}

The use of advanced analytics has led to the development of programmatic advertising (or real-time advertising); where buyers and sellers of online advertising connect to exchange available inventory (Busch, 2016; Rayport, 2015). The programmatic advertising environment offers remarkable speeds and sophistication levels, as online users click on URLs. In a short period (less than a second), an algorithm evaluates an optimal bid for an advertiser. As a result, a real-time auction determines the winning bid (Jerath and Savary, 2017). Consequentially, the winning ad is displayed, and the advertiser is notified that the ad had been viewed by online prospects. The analytics technology has enabled the technology giants to deliver targeting and re-targeting solutions with instantaneous pricing and access, across digital channels (including; mobile, video, social, etc.) (Rayport, 2015). Therefore, programmatic advertising is set to continue captivating the cross-media creative and media industry as it forms the basis of distributive advertising and marketing on every level (Busch, 2016). Another disruptive innovation, namely, blockchain's distributed ledger technology involves a decentralised environment where online transactions are recorded in a public ledger that are visible to everyone (Wang et al., 2018a; Yli-Huumo et al., 2016). Blockchain is a new platform technology enabling an improved ability to verify and record the exchange of value among an interconnected set of users. It is a secure and transparent way to track the ownership of assets before, during, and after any transaction (Lakhani, 2017; Yli-Huumo et al., 2016). Hence, it may appear that this technology meets the user's confidentiality and consistency requirements.

In the past, companies could have struggled to determine the value of their intellectual property; including patents and trade secrets. However, emerging blockchain technologies create marketplaces for such intangible data, whilst improving data privacy. Blockchain has stringent requirements for privacy and confidentiality, but also for auditability (FEDS, 2016). Hence, organisations are increasingly sharing their data in a safe environment, because there's more protection in terms of cryptography and protocols. Blockchain users track the ownership of assets before, during, and after any online transaction. Therefore, its distributed ledger technology can be used by different businesses hailing from various industry sectors, to facilitate their transactions with marketplace stakeholders, including suppliers, intermediaries, and consumers across borders. Blockchain records a history of all transactions within it, and all users in the network have an identical copy of the record/ledger. The network using the blockchain agrees on and governs the rules for its use. It protects all data and information, and the use of digital keys and digital signatures is required to access data in the ledger (Lakhani, 2017). The blockchain's data is permanent and the details of all recorded transactions cannot be altered retroactively without the full agreement of the network.

Moreover, the blockchain's digital ledger reflects any changes in real-time, and the records of all transactions are securely maintained and updated by the users themselves. These benefits enable the development of many potential products and applications for different industry practitioners, including government entities and business organisations. Current blockchain products include: 
1 the clearing of payments and settlement functions in financial services companies

2 the creation and use of a digital identity within an enterprise

3 smart contracts (Iansiti and Lakhani, 2017; Yli-Huumo et al., 2016; Kosba et al., 2016), among other applications.

Blockchain can facilitate cross-borders payments among marketplace stakeholders, including; suppliers, intermediaries, and consumers. Very often, the businesses' payment options are highly intermediated, costly, and time consuming. Additionally, the blockchain's online transactions are secure, private, and verifiable (Iansiti and Lakhani, 2017). This technology could potentially lead to operational efficiencies and cost savings that may be passed on to the consumers themselves. On the other hand, many commentators maintain that blockchain has potential challenges and limitations in terms of its scalability issues. The distributed ledger technology's performance is limited by the network's latency (Wang et al., 2018a, 2018b). Currently, blockchain is restricted by its transaction speeds. For instance, the maximal transaction throughput of the Bitcoin is 27 transactions per second (Georgiadis, 2019).

\section{Discussion and conclusions}

Overall, it may appear that the data-driven marketing technologies are supporting the businesses' marketing mix elements as they improve their interactive engagement with individual prospects. This contribution posited that they can even enhance customer-centric marketing, in terms of the increased personalisation of services, whilst providing secure pricing options. Evidently, many firms are evolving from their passive, rigid, and product-centric state to a more flexible, dynamic, and customer-focused environment, as they monitor and detect any changes in consumer sentiment. Data-driven companies are increasingly capturing and analysing the online and mobile activity of prospective customers, as they delve into ecommerce and review sites, personal blogs and social media (Kumar et al., 2017). Their analytics captures the consumers' interactions with brands and companies through digital media. Therefore, big data is enabling them to target and re-target individuals and online communities with instantaneous pricing and access options, across multiple channels (via web-site activity, mobile, video, social media, ecommerce, among others). Large technology giants use mobile tracking technologies, to gather information on the consumer behaviours, including their shopping habits, lifestyle preferences, etc. (Aksu et al., 2018).

Tech-savvy firms have learnt how to take advantage of on-demand, real-time information from sensors, radio frequency identification and other geo-location tracking devices to better understand their marketing environments at a more granular level (Storey and Song, 2017; Kwon et al., 2014). This way business could come up with personalised products and services that are demanded by individual customers themselves (Li et al., 2017). The challenge for many business practitioners is to recognise the value of big data analytics as they can truly provide insightful information on the marketing environment, including customers and the competitors (Grover et al., 2018). The predictive-analytical tools can examine different scenarios; as the prescriptive analytics anticipate what shall happen in the future. Such digital technologies monetise data by identifying revenue-generating opportunities and/or through the identification of cost 
savings. The use of the big data analytics' automated inferences and data modelling can provide quick and effective reaction to new opportunities, threats or regulations, thereby increasing the business's agility (Erevelles et al., 2016). From a business perspective, it may prove difficult to manage data in an efficient manner, as internal as well as external data may often be unstructured or loosely structured.

However, recently there have been significant advances in technological innovations in mobile, social media, video streaming, wearable devices, virtual and augmented reality, 5G networks and the internet-of-things (IoT), among others. These disruptive technologies have inevitably provided new opportunities to acquire more information from the marketing environment. For instance, many businesses are already benefiting of the programmatic advertising environment; whereby buyers and sellers of digital advertising are increasingly connecting online to exchange available inventory (Malthouse and Li, 2017; Busch, 2016). The perennial issue is whether businesses will (or will not) continue to rely on the insights from big data analytics to improve their organisational performance. Nevertheless, this contribution posited that the data-driven technologies are helping businesses to achieve a competitive advantage. For instance, a relevant literature review suggests that the blockchain applications can be used by businesses to facilitate their transactions with marketplace stakeholders, including suppliers, intermediaries, and consumers across borders (Wang et al., 2018b; Lakhani, 2017). Despite its inherent limitations, the blockchain's distributed ledger technology will probably be more convenient than other payment options, in terms of time and money. Therefore, blockchain can possibly offer better customer service levels and operational efficiencies for the many businesses. At the same time, this paper reported that it has improved the data privacy among an interconnected set of online users, as it tracks the ownership of assets before, during, and after any online transaction.

This paper reported that smart, data-driven technologies are shifting how organisations collect, analyse and utilise and distribute data (Hashem et al., 2016; George et al., 2014). Table 1 illustrates how insightful data is increasingly being captured through online and mobile activity. Hence, this data is analysed and/or distributed for monetisation or strategic purposes.

Table 1 The data processing cycle

\begin{tabular}{ll}
\hline Capturing data & Online and mobile users' behaviour in real-time \\
& Customer service records \\
& Referral sources and product recommender systems \\
& Consumers' personal preferences \\
& Website activity \\
& Social media networks \\
& Ecommerce platforms \\
& Comprehensive information in a database \\
& Descriptive analytics \\
Analysing data & Predictive analytics \\
& Prescriptive analytics \\
& Programmatic advertising \\
Distributing data & Blockchain distributed ledger technology
\end{tabular}




\section{Emerging trends and future research}

Disruptive technologies can be used to anticipate the discerned consumers' requirements. For example, the use of programmatic advertising will probably increase the individuals' intuitive shopping experiences and can tap into the travellers' discretionary purchases.

In the foreseeable future, it is very likely that there will be more sales via mobile commerce, with increased consumer interactions through speech and voice recognition software. The service providers may possibly rely on artificial intelligence (AI) and other forms of cognitive learning capabilities, like machine learning and deep learning. Many businesses' distributive systems could interface with virtual reality software to help online intermediaries to merchandise their products in captivating customer experiences. Notwithstanding, online consumers may possibly use blockchain's secure technology to purchase products through their mobile devices.

In conclusion, this contribution calls for further empirical research that could explore the use of data-driven marketing innovations to better serve individuals and organisations. Future research avenues may include; the personalisation and behavioural modelling for mobile apps, programmatic advertising, blockchain, AI, and IoT, among other areas.

\section{Acknowledgements}

The author thanks the editor as well as the reviewers for their constructive remarks and suggestions. Their feedback has improved the quality of this contribution.

\section{References}

Abbasi, A., Sarker, S. and Chiang, R.H. (2016) 'Big data research in information systems: toward an inclusive research agenda', Journal of the Association for Information Systems, Vol. 17, No. 2, pp.1-32.

Aksu, H., Babun, L., Conti, M., Tolomei, G. and Uluagac, A.S. (2018) 'Advertising in the IoT era: vision and challenges', IEEE Communications Magazine, Vol. 99, pp.1-7.

Akter, S., Wamba, S.F., Gunasekaran, A., Dubey, R. and Childe, S.J. (2016) 'How to improve firm performance using big data analytics capability and business strategy alignment?', International Journal of Production Economics, Vol. 182, pp.113-131.

Andrejevic, M. (2014) 'Big data, big questions the big data divide', International Journal of Communication, Vol. 8, pp.1673-1689.

Baesens, B., Bapna, R., Marsden, J.R., Vanthienen, J. and Zhao, J.L. (2016) 'Transformational issues of big data and analytics in networked business', MIS Quarterly, Vol. 40, No. 4, pp.807-818.

Boucher Ferguson, R. (2013) 'Is digital advertising a new form of market manipulation?', MIT Sloan [online] http://sloanreview.mit.edu/article/is-digital-advertising-a-new-form-of-marketmanipulation/ (accessed 20 May 2018).

Boyd, D. and Crawford, K. (2012) 'Critical questions for big data. Information', Communication and Society, Vol. 15, No. 5, pp.662-679.

Buhalis, D. and Amaranggana, A. (2013) 'Smart tourism destinations', in Information and Communication Technologies in Tourism 2014, pp.553-564, Springer, Cham, Switzerland.

Busch, O. (2016) 'The programmatic advertising principle', in Programmatic Advertising, pp.3-15, Springer, Cham, Switzerland. 
Cambria, E. (2016) 'Affective computing and sentiment analysis', IEEE Intelligent Systems, Vol. 31, No. 2, pp.102-107.

Camilleri, M.A. (2015) 'Using big data for customer-centric marketing, Handbook of Research on Open Data Innovations in Business and Government, IGI Global, Hershey, USA.

Camilleri, M.A. (2018a) 'The promotion of responsible tourism management through digital media', Tourism Planning \& Development, Vol. 15, No. 6, pp.653-671.

Camilleri, M.A. (2018b) 'The SMEs' technology acceptance of digital media for stakeholder engagement', Journal of Small Business and Enterprise Development [online] https://doi.org/ 10.1108/JSBED-02-2018-0042.

Camilleri, M.A. (2018c) 'Tourism distribution channels', in Camilleri, M.A. (Ed.): Travel Marketing, Tourism Economics and the Airline Product, Springer, Cham, Switzerland.

Chen, C.P. and Zhang, C.Y. (2014) 'Data-intensive applications, challenges, techniques and technologies: a survey on big data', Information Sciences, Vol. 275, No. 10, pp.314-347.

Chen, H., Chiang, R.H. and Storey, V.C. (2012) 'Business intelligence and analytics: from big data to big impact', MIS Quarterly, Vol. 36, No. 4, pp.1165-1188.

Cheng, M. and Edwards, D. (2015) 'Social media in tourism: a visual analytic approach', Current Issues in Tourism, Vol. 18, No. 11, pp.1080-1087.

Côrte-Real, N., Oliveira, T. and Ruivo, P. (2017) 'Assessing business value of big data analytics in European firms', Journal of Business Research, Vol. 70, pp.379-390.

Davenport, T. (2014) 'How strategists use 'big data' to support internal business decisions, discovery and production', Strategy and Leadership, Vol. 42, No. 4, pp.45-50.

Davenport, T.H., Barth, P. and Bean, R. (2012) 'How 'big data' is different', MIT Sloan Management Review [online] https://sloanreview.mit.edu/article/how-big-data-is-different/ (accessed 15 May 2018).

Deka, G.C. (2016) 'Big data predictive and prescriptive analytics', in Big Data: Concepts, Methodologies, Tools, and Applications, pp.30-55, IGI Global, Hershey, USA.

EMarketer (2018) More than 80\% of Digital Display Ads Will Be Bought Programmatically in 2018 [online] https:/www.emarketer.com/content/more-than-80-of-digital-display-ads-willbe-bought-programmatically-in-2018 (accessed 23 May 2018).

Erevelles, S., Fukawa, N. and Swayne, L. (2016) 'Big data consumer analytics and the transformation of marketing', Journal of Business Research, Vol. 69, No. 2, pp.897-904.

EU (2018) 2018 Reform of EU Data Protection Rules, EU Commission, Brussels, Belgium [online] https://ec.europa.eu/commission/priorities/justice-and-fundamental-rights/data-protection/ 2018-reform-eu-data-protection-rules_en (accessed 2 May 2018).

FEDS (2016) Distributed Ledger Technology in Payments, Clearing, and Settlement, Finance and Economics Discussion Series Divisions of Research and Statistics and Monetary Affairs, Federal Reserve Board, Washington, DC [online] https:/www.federalreserve.gov/econresdata/ feds/2016/files/2016095pap.pdf (accessed 14 May 2018).

Fong, N.M., Fang, Z. and Luo, X. (2015) 'Geo-conquesting: competitive locational targeting of mobile promotions', Journal of Marketing Research, Vol. 52, No. 5, pp.726-735.

Frizzo-Barker, J., Chow-White, P.A., Mozafari, M. and Ha, D. (2016) 'An empirical study of the rise of big data in business scholarship', International Journal of Information Management, Vol. 36, No. 3, pp.403-413.

Fu, Y., Hao, J.X., Li, X. and Hsu, C.H. (2018) 'Predictive accuracy of sentiment analytics for tourism: a metalearning perspective on Chinese travel news', Journal of Travel Research [online] http://journals.sagepub.com/doi/abs/10.1177/0047287518772361 (accessed 25 May 2018).

Gandomi, A. and Haider, M. (2015) 'Beyond the hype: big data concepts, methods, and analytics', International Journal of Information Management, Vol. 35, No. 2, pp.137-144. 
Gao, S., Tang, O., Wang, H. and Yin, P. (2018) 'Identifying competitors through comparative relation mining of online reviews in the restaurant industry', International Journal of Hospitality Management, Vol. 71, pp.19-32.

George, G., Haas, M.R. and Pentland, A. (2014) 'Big data and management', Academy of Management Journal, Vol. 57, No. 2, pp.321-326.

Georgiadis, E. (2019) How Many Transactions Per Second Can Bitcoin Really Handle?, Theoretically, Cryptology ePrint Archive, Report 2019/416 [online] https://eprint.iacr.org/ 2019/416 (accessed 2 May 2019).

Goddard, M. (2017) 'The EU General Data Protection Regulation (GDPR): European regulation that has a global impact', International Journal of Market Research, Vol. 59, No. 6, pp.703-705.

Gretzel, U., Sigala, M., Xiang, Z. and Koo, C. (2015) 'Smart tourism: foundations and developments', Electronic Markets, Vol. 25, No. 3, pp.179-188.

Grover, V., Chiang, R.H., Liang, T.P. and Zhang, D. (2018) 'Creating strategic business value from big data analytics: a research framework', Journal of Management Information Systems, Vol. 35, No. 2, pp.388-423.

Halavais, A. (2015) 'Bigger sociological imaginations: framing big social data theory and methods', Information, Communication and Society, Vol. 18, No. 5, pp.583-594.

Hartmann, P.M., Zaki, M., Feldmann, N. and Neely, A. (2016) 'Capturing value from big data - a taxonomy of data-driven business models used by start-up firms', International Journal of Operations and Production Management, Vol. 36, No. 10, pp.1382-1406.

Hashem, I.A.T., Chang, V., Anuar, N.B., Adewole, K., Yaqoob, I., Gani, A, Ahmed, E. and Chiroma, H. (2016) 'The role of big data in smart city', International Journal of Information Management, Vol. 36, No. 5, pp.748-758.

Horlacher, A. and Hess, T. (2016) 'What does a chief digital officer do? Managerial tasks and roles of a new C-level position in the context of digital transformation', in 2016 49th Hawaii International Conference on System Sciences (HICSS), IEEE, pp.5126-5135.

Iansiti, M. and Lakhani, K.R. (2017) 'The truth about blockchain', Harvard Business Review, Vol. 95, No. 1, pp.118-127.

Jerath, K. and Savary, M. (2017) A Primer on Programmatic Advertising, Columbia University, NY, USA.

Ji-fan Ren, S., Fosso Wamba, S., Akter, S., Dubey, R. and Childe, S.J. (2017) 'Modelling quality dynamics, business value and firm performance in a big data analytics environment', International Journal of Production Research, Vol. 55, No. 17, pp.5011-5026.

Kosba, A., Miller, A., Shi, E., Wen, Z. and Papamanthou, C. (2016) 'The blockchain model of cryptography and privacy-preserving smart contracts', in 2016 IEEE Symposium on Security and Privacy (SP), IEEE, pp.839-858.

Kumar, V., Choi, J.B. and Greene, M. (2017) 'Synergistic effects of social media and traditional marketing on brand sales: capturing the time-varying effects', Journal of the Academy of Marketing Science, Vol. 45, No. 2, pp.268-288.

Kwon, O., Lee, N. and Shin, B. (2014) 'Data quality management, data usage experience and acquisition intention of big data analytics', International Journal of Information Management, Vol. 34, No. 3, pp.387-394.

Lakhani, K. (2017) Blockchain - What You Need to Know [online] https://hbr.org/ideacast/2017/06/ blockchain-what-you-need-to-know (accessed 28 April 2018).

Li, Y., Hu, C., Huang, C. and Duan, L. (2017) 'The concept of smart tourism in the context of tourism information services', Tourism Management, Vol. 58, pp.293-300.

Liu, Y., Teichert, T., Rossi, M., Li, H. and Hu, F. (2017) 'Big data for big insights: investigating language-specific drivers of hotel satisfaction with 412,784 user-generated reviews', Tourism Management, Vol. 59, pp.554-563. 
Loebbecke, C. and Picot, A. (2015) 'Reflections on societal and business model transformation arising from digitization and big data analytics: a research agenda', Journal of Strategic Information Systems, Vol. 24, No. 3, pp.149-157.

Malthouse, E.C. and Li, H. (2017) 'Opportunities for and pitfalls of using big data in advertising research', Journal of Advertising, Vol. 46, No. 2, pp.227-235.

Nichols, W. (2013) 'Advertising Analytics 2.0', Harvard Business Review, March [online] https://hbr.org/2013/03/advertising-analytics-20 (accessed 20 May 2018).

Pan, B. and Yang, Y. (2017) 'Forecasting destination weekly hotel occupancy with big data', Journal of Travel Research, Vol. 56, No. 7, pp.957-970.

Ransbotham, S. and Kiron, D. (2018) 'Using analytics to improve customer engagement', MIT Sloan Management Review [online] https://sloanreview.mit.edu/projects/using-analytics-toimprove-customer-engagement/ (accessed 21 May 2018).

Ransbotham, S., Kiron, D. and Prentice, P.K. (2015) 'Minding the analytics gap', MIT Sloan Management Review, Vol. 56, No. 3, pp.63-68.

Rayport, J.F. (2015) 'Is programmatic advertising the future of marketing?', Harvard Business Review [online] https://hbr.org/2015/06/is-programmatic-advertising-the-future-of-marketing (accessed 23 May 2018).

Russell Neuman, W., Guggenheim, L., Mo Jang, S. and Bae, S.Y. (2014) 'The dynamics of public attention: agenda-setting theory meets big data', Journal of Communication, Vol. 64, No. 2, pp.193-214.

Siegel, E. (2016) Predictive Analytics: The Power to Predict Who Will Click, Buy, Lie, or Die, Wiley, New York, USA.

Siegel, E. and Davenport, T.H. (2013) Predictive Analytics: The Power to Predict Who Will Click, Buy, Lie, or Die, Wiley, New York, USA.

Stergiou, C., Psannis, K.E., Kim, B.G. and Gupta, B. (2018) 'Secure integration of IoT and cloud computing', Future Generation Computer Systems, Vol. 78, pp.964-975.

Storey, V.C. and Song, I.Y. (2017) 'Big data technologies and management: what conceptual modeling can do?', Data and Knowledge Engineering, Vol. 108, pp.50-67.

Wang, G., Gunasekaran, A., Ngai, E.W. and Papadopoulos, T. (2016) 'Big data analytics in logistics and supply chain management: certain investigations for research and applications', International Journal of Production Economics, Vol. 176, pp.98-110.

Wang, B., Chen, S., Yao, L., Liu, B., Xu, X. and Zhu, L. (2018a) 'A simulation approach for studying behavior and quality of blockchain networks', in International Conference on Blockchain, pp.18-31, Springer, Cham.

Wang, Y., Kung, L. and Byrd, T.A. (2018b) 'Big data analytics: understanding its capabilities and potential benefits for healthcare organizations', Technological Forecasting and Social Change, Vol. 126, pp.3-13.

Woerner, S.L. and Wixom, B.H. (2015) 'Big data: extending the business strategy toolbox', Journal of Information Technology, Vol. 30, No. 1, pp.60-62.

Xiang, Z., Du, Q., Ma, Y. and Fan, W. (2017) 'A comparative analysis of major online review platforms: implications for social media analytics in hospitality and tourism', Tourism Management, Vol. 58, pp.51-65.

Yli-Huumo, J., Ko, D., Choi, S., Park, S. and Smolander, K. (2016) 'Where is current research on blockchain technology? - A systematic review', PloS One, Vol. 11, No. 10, pp.1-27. 